\title{
Adult female acne: a guide to clinical practice ${ }^{*}$
}

\author{
Edileia Bagatin ${ }^{1,2}$, Thais Helena Proença de Freitas ${ }^{3,4}$, Maria Cecilia Rivitti-Machado, ${ }^{5,6}$, Beatriz Medeiros \\ Ribeiro $^{7}$, Samanta Nunes ${ }^{8}$, Marco Alexandre Dias da Rocha ${ }^{9}$
}

DOI: http:/ / dx.doi.org/10.1590/abd1806-4841.20198203

\begin{abstract}
BACKGROUND: Acne in women is often associated with anxiety and depression, and may persist from adolescence as well as manifest for the first time in adulthood. Genetic and hormonal factors contribute to its etiopathogenesis, and maintenance treatment is required, usually for years, due to its clinical evolution.

ОвлестіvE: To develop a guide for the clinical practice of adult female acne.

METHODS: A team of five experts with extensive experience in acne conducted a literature review of the main scientific evidence and met to discuss the best practices and personal experiences to develop a guide containing recommendations for the clinical practice of adult female acne.

RESULTS: The group of specialists reached consensus on the main guidelines for clinical practice, providing detailed recommendations on clinical picture, etiopathogenesis, laboratory investigation and treatment of adult female acne.

ConCLuSION: Different from teenage acne, adult female acne presents some characteristics and multiple etiopathogenic factors that make its management more complex. This guide provides recommendations for best clinical practices and therapeutic decisions. However, the authors consider that additional studies are needed in order to provide more evidence for adult female acne to be better understood.
\end{abstract}

Keywords: Acne vulgaris; Adult; Advanced treatment; Consensus; Hormones; Hyperandrogenism; Skin; Therapeutics

\section{INTRODUCTION}

Acne affects an increasing number of adult females, impairing quality of life, with significant negative psychological effect and social impact. Adult female acne (AFA) is defined as one that affects women over the age of 25 and may persist continuously or intermittently from adolescence or manifest for the first time in this period. It is believed that genetic and hormonal factors contribute to the pathogenesis of AFA, characterized by chronic evolution, requiring maintenance treatment, in some cases for years. ${ }^{1-4}$
In 1979, a publication showed that acne in adults over 18 years of age was relatively common, persisting in $5 \%$ of females between the ages of 40 and $49 .{ }^{5}$ Only in 1997 did acne in adults, older than 25 years of age, begin to gain more attention, showing that $76 \%$ of these patients were women with a mean age of 35.5 years. Most of the cases were from persistent acne and only $18.4 \%$ of females had late acne, starting after 25 years, mainly due to hyperandrogenism changes. ${ }^{3}$ Other studies have confirmed that persistent acne is more common than acne beginning in adulthood..$^{6,7}$

\footnotetext{
Received 18 February 2018.

Accepted 10 June 2018.

* Work conducted at the Department of Dermatology, Escola Paulista de Medicina, Universidade Federal de São Paulo, São Paulo (SP), Brazil. Financial support: None.

Conflict of interest: Dr. Samanta Nunes is a medical consultant at Bayer.

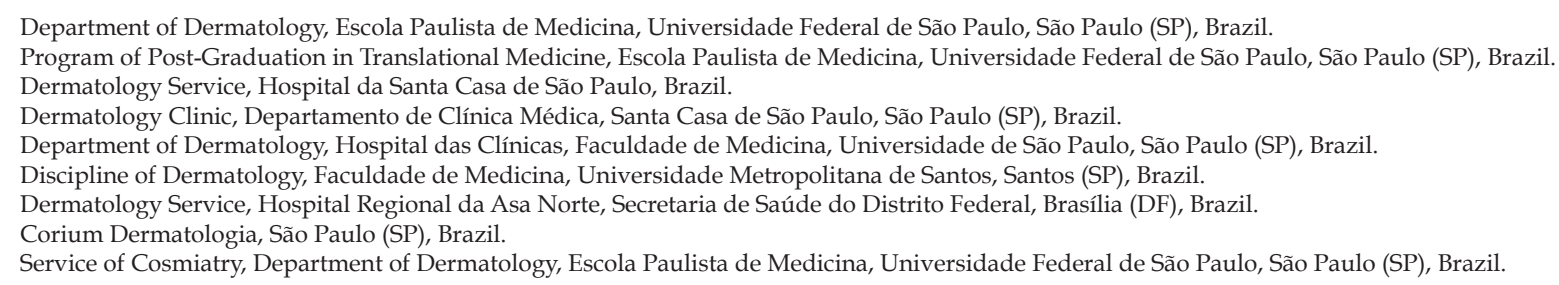


Other authors have confirmed that adult females are more affected than men in all age groups and that acne can persist even after 50 years of age.

In addition to persistent and late acne, more recently a third type has been suggested, called recurrent acne, that is present in adolescence, improves for a variable period of time, and returns in adulthood. There are few publications regarding this, because current researches, despite questioning the age of onset of acne, rarely ask the patient if acne recurred after a period in adolescence. ${ }^{8}$ Some authors suggest two categories of AFA: 25 to 44 years of age and over 45 years of age in the period near menopause, but the characteristics of each group still need to be better defined. ${ }^{9}$

\section{CLINICAL CONDITION}

The first studies showed that the AFA lesions were located mainly on the lower part of the face, including the mandibular region, the perioral region and the chin, conferring a U-shape, in addition to the anterior cervical region. It is characterized by inflammatory lesions, papules and pustules, of mild to moderate intensity, with the presence of few closed comedones or microcysts. Postinflammatory hyperpigmentation is common and scars can occur in $20 \%$ of affected women. ${ }^{10}$ In addition, the skin may be more sensitive than that of adolescents, with less tolerance to topical medications. ${ }^{8,11}$ Table 1 demonstrates two clinical forms of AFA, according to the classification of Preneau and Dreno. ${ }^{8}$

Recently, the classic AFA location on the lower third of the face was questioned. ${ }^{9}$ Studies have observed cases with localization on other areas of the face and back. One study showed that most women $(89.8 \%)$ had involvement of multiple facial areas, such as the forehead, malar region, mandibular area and temporal region, with a similar severity spectrum to adolescents. The most common clinical presentation was mixed facial acne, with noninflammatory and inflammatory lesions. The majority of the women $(93.7 \%)$ had comedones, and $48.4 \%$ presented lesions on the trunk and only $11.2 \%$ on the mandibular regions. ${ }^{1}$

\section{Severity scales}

It is believed that AFA is different from juvenile acne due to its clinical evolution. ${ }^{12}$ Scales have been developed to validate a severity score for each type of acne and thus ensure the best treatment. These include the GEA (Global Evaluation Acne) scale and, more recently, the AFAST (Adult Female Acne Scoring Tool), which includes the submandibular region evaluation, as shown in table 2.12,13

\begin{tabular}{lll}
\hline \multicolumn{3}{c}{ TABLE 1: Clinical forms of adult female acne } \\
$\begin{array}{l}\text { CLINICAL } \\
\text { FORM }\end{array}$ & CHARACTERISTICS & $\begin{array}{l}\text { PRODUCTION } \\
\text { OF SEBUM }\end{array}$ \\
\hline $\begin{array}{l}\text { Inflammatory } \\
\text { (affects } 58 \% \\
\text { of females) }\end{array}$ & $\begin{array}{l}\text { Papules, pustules and } \\
\text { nodules that lead to the } \\
\text { formation of scars }\end{array}$ & $\begin{array}{l}\text { Increased } \\
\text { seborrhea is not } \\
\text { always present }\end{array}$ \\
$\begin{array}{ll}\text { Retentional } \\
\text { comedones and } \\
\text { microcysts; small } \\
\text { number of inflammatory } \\
\text { lesions }\end{array}$ & $\begin{array}{l}\text { Increased } \\
\text { seborrhea is } \\
\text { always present } \\
\text { and lesions } \\
\text { appear all over } \\
\text { the face }\end{array}$ \\
\hline
\end{tabular}

Adapted from: Preneau and Dreno, $2012^{8}$

\section{ETHIOPATHOGENESIS}

The etiopathogenesis of acne vulgaris involves a complex interaction between the main factors such as: genetic predisposition; androgenic hormone stimulation leading to an increase in sebaceous secretion; alteration of the lipid composition; follicular hyperkeratinization; bacterial colonization mainly by Propionibacterium acnes (P. acnes) and periglandular dermal inflammation. ${ }^{14}$ Currently, inflammation is considered a key component and can be detected on histopathological and immunohistochemical examination in apparently non-inflammatory acneic lesions such as comedones and even in perilesional areas, without lesions (subclinical).$^{15,16}$

The causes of AFA have not yet been fully elucidated. Several other factors have been postulated as triggers or aggravating factors, such as: exposure to ultraviolet radiation, stress, obesity, diet, smoking, sleep disorders, cosmetics, medications, excessive skin washing, possible resistance to $P$. acnes and endocrine deficiency diseases. ${ }^{1}$ Currently, the deficiency of the epidermal barrier function has also been reported as a relevant change. The damage of the barrier and the consequent increase in transepidermal water loss may be responsible for the onset of the inflammatory cascade that constitutes the central change in the onset of acne. ${ }^{17,18}$ Figure 1 presents the main etiopathogenical factors in AFA.

TABLE 2: AFAST rating scale for adult female acne

AFAST SCALE (Adult Female Acne Scoring Tool)

Score 1: Assess the severity of acne on face (GEA SCORE)

0 No acne lesions Residual pigmentation or erythema or almost no

lesions

1 Almost no lesions Few open or closed comedones - Few papules

2 Mild

3 Moderate More than half of the face involved - Numerous papules, pustules, comedones and up to a nodule

4 Severe Entire face - Numerous papules, pustules, comedones and rare nodules

5 Very Severe Very inflammatory on the entire face, with nodules

Score 2: Assess the severity of acne in the submandibular zone

0 No lesions - Erythema and postinflammatory hyperpigmentation

1 Rare papules, pustules and/or comedones

2 Few papules, pustules and/or comedones - Less than 25\% of the affected area - A nodule/cyst may be present

3 Numerous papules, pustules and/or comedones and at least $25 \%$ of the affected area - Two or more nodules/cysts

Adapted from Aufret, et al, $2016^{12}$ 


\section{Genetics}

Genetic predisposition has been considered an important predisposing factor, influencing the number, size and activity of the sebaceous glands. Its influence on hormonal control has also been observed, as well as on the process of follicular hyperkeratinization and on innate immunity. In one study, adult women with acne reported first-degree relatives with acne in adulthood. ${ }^{19}$

\section{Hormones}

The role of androgens in the etiopathogenesis of acne vulgaris is well established. Testosterone, Dehydroepiandrosterone Sulfate (SDHEA) and Dihydrotestosterone (DHT) stimulate sebaceous gland growth and sebum production. Estrogens have the opposite effect, that is, they inhibit the secretion of androgens, modulate genes involved in the growth of the sebaceous gland and inhibit their function. The activity of the sebaceous gland therefore depends on the estrogen/androgen ratio..$^{20}$

In relation to AFA and hormones, the following are outstanding:

1) Increased sensitivity of the sebaceous gland to androgenic hormones: As in acne vulgaris, in AFA there is an increase in the number and sensitivity of the receptors located in sebocytes and keratinocytes to circulating androgenic hormones.

2) Increased peripheral hormonal conversion: sebocytes and keratinocytes present an enzymatic system capable of locally producing testosterone and DHT. Hyperactivity and abnormal activity of enzymes related to the metabolism of androgenic hormones such as 5-alpha reductase, 3-beta-hydroxysteroid dehydrogenase and 17-hydroxysteroid dehydrogenase, with increased pre-hormone peripheral conversion (SDHEA, androstenedione and testosterone) into more potent androgenic hormones (testosterone and DHT). DHT is 5 to 10 times more potent than its precursor, testosterone, and less likely to be metabolized by aromatase into estrogen. ${ }^{20}$

3) Worsening of the disease in the premenstrual period in 60 to $70 \%$ of women, as well as in premenopausal, pregnancy and during the use of progestin-only contraceptives. In these periods there is a relative increase of the hormones with greater androgenic activity, in relation to estradiol.

4) Other hormones, besides androgens and estrogens, regulate the production of sebum: the sebaceous gland is a neuroendocrine organ and the production of sebum can also be stimulated, in periods of stress, by neuropeptides and hormones such as melanocortins and corticotropin-releasing hormone (CRH) ${ }^{21} \mathrm{CRH}$ increases the expression of $3 \beta$-hydroxy-steroid dehydrogenase mRNA, the enzyme responsible for the conversion of dihydroepiandrosterone (DHEA) to testosterone. Also neuropeptides, histamine, retinoids, vitamin D and insulin-like growth factor 1 (IGF-1) have been described as regulators of sebum production.

\section{Changes in sebum}

Qualitative changes were verified in the components of sebum in the skin with acne. There is a relative decrease of Linoleic Acid (AL), an Essential Fatty Acid (EFA), protector of the glandular epithelial wall. There is also the peroxidation of squalene by the combined action of $P$. acnes and ultraviolet radiation. These alterations and the presence of free fatty acids resulting from the hydrolysis of triglycerides, through the action of lipases released by $P$. acnes, cause damage the epithelium, increasing infundibular keratinization and dermal inflammation. ${ }^{14}$

\section{Follicular hyperkeratinizatin}

There is an abnormal proliferation of keratinocytes, stimulated by pro-inflammatory cytokines, such as interleukin-1 alpha (IL-1 alpha). This cytokine is triggered by the activation of Toll-like receptors or TLR 2 and 4, related to innate immunity, which recognize molecular patterns present in P. acnes, as well as sebaceous hyper-secretion and squalene peroxidation. ${ }^{14}$ The formation of the micro-comedone is also preceded by a mononuclear infiltrate formed mainly by CD4+ T lymphocytes and CD68+ macrophages, which corroborates to the hypothesis of the participation of the inflammatory process in the early stages of acne. ${ }^{22}$

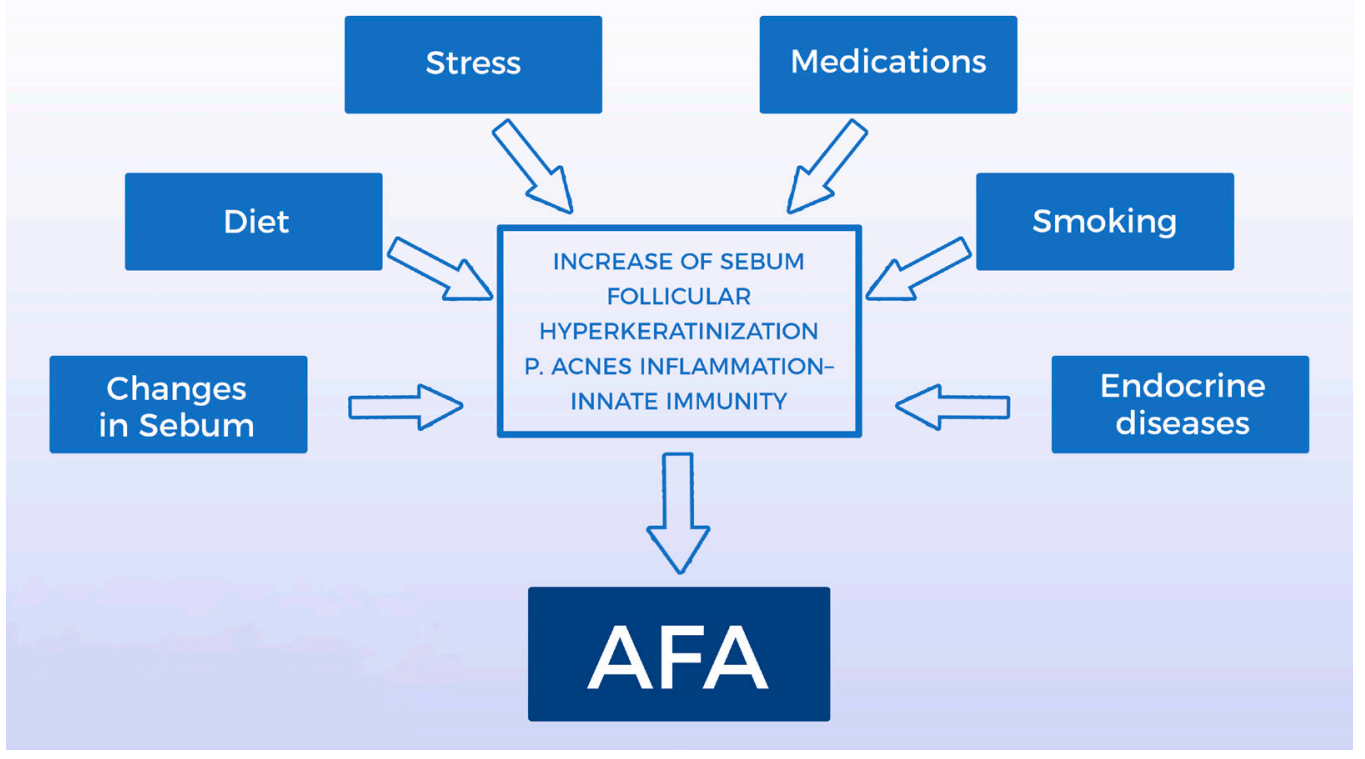

Figure 1: Main etiopathogenic factors of adult female acne (AFA) loped by the authors 


\section{Bacterial colonization}

The main bacterium involved in the pathogenesis of acne is $P$. acnes. It is a Gram-positive anaerobic bacterium that makes up the microbiome of the skin, being located preferably in the seborrheic areas. In skin with acne there is an exaggerated growth of the population of $P$. acnes. ${ }^{23} P$. acnes is involved in several mechanisms: stimulation of follicular hyper-keratinization; alteration of the sebaceous composition; and inflammatory response through TLR activation. In addition, it produces several enzymes, such as lipases, proteases, hyaluronidases, endoglyceramidase, sialidase/neuroaminidase, proteinase and 5 cAMP factors, which contribute to follicular rupture and tissue degradation. ${ }^{24}$

\section{Immuno-inflammatory processes}

Upon recognition of the $P$. acnes molecular patterns, TLR 2 and 4 are activated, triggering an inflammatory cascade through the nuclear pathway NFk $\beta$, with production of pro-inflammatory cytokines or interleukins and tumor necrosis factor alpha (TNF-alpha) that recruit neutrophils and macrophages, maintaining the inflammatory cycle. Activation of TLR leads to the release of antimicrobial peptides such as beta-defensins 1 and 2, cathelecidins and granulolysins. A second nuclear pathway is also activated - pathway AP1, with release of metalloproteinases 1, 3 and 9 that degrade the extracellular dermal matrix and are associated with the formation of scars..$^{25}$

\section{Other factors}

Diet

Studies have shown that consumption of high glycemic and dairy foods increases insulin and IGF1 levels. The gonads and sebaceous glands have receptors for both hormones which stimulate the production of androgens, such as testosterone, and inhibit the action of aromatase that converts testosterone to estradiol. The nutritional status of the cell is recognized initially by the transcription factors FOX01 and the signaling pathway mTORC1. ${ }^{26}$ High glycemic load foods, dairy products, increased insulin and IGF1 stimulate $\mathrm{mTORC1}$, triggering processes such as: increased protein and lipid synthesis, cell proliferation, cell differentiation with acroinfundibular hyper-proliferation of keratinocytes, sebaceous gland hyperplasia, increased sebaceous lipogenesis, insulin resistance and increased body mass index. ${ }^{26}$ In addition to the diet rich in foods with a high glycemic load and the consumption of dairy products, worsening of acne by the use of dietary supplements for muscle mass gains that are rich in branched-chain amino acids and peptides derived from whey is observed in daily practice. ${ }^{27}$

\section{Drugs}

Certain medications are associated with the development of acne, such as benzodiazepines, lithium, cyclosporin, ramipril, isoniazid, iodides, bromides, vitamin B-type complexes, serotonin uptake inhibitors, epidermal growth receptor inhibitors and progestin contraceptives. ${ }^{28-30}$ First-generation progestins such as norgestrel and levonorgestrel have androgenic effect similar to testosterone. ${ }^{31}$ Corticosteroids stimulate hyperkeratinization and increase the expression of TLR $2 .^{28}$

Authors have noted that levonorgestrel intrauterine devices, subcutaneous etonorgestrel and levonorgestrel implants, and long-acting methods with progestin alone may have a negative effect on acne or may trigger acne in predisposed women. ${ }^{32-34} \mathrm{~A}$ prospective study showed that $10 \%$ of 80 women who used subcutaneous implants with etonorgestrel had acne. ${ }^{33}$ Another multicenter, randomized, controlled study of subcutaneous implants with etonorgestrel or levonorgestrel compared to copper intrauterine devices showed that acne was more frequent in the group with implants. ${ }^{34}$ However, it is important to consider other causes for the appearance of acne in these cases, such as the suspension of estrogen-containing oral contraceptives. ${ }^{32}$

\section{Stress}

Stress stimulates the release of pro-inflammatory cytokines and $\mathrm{CRH}$, leading to increased levels of cortisol. Recent studies show that sleep deprivation associated with women's modern lifestyle and stress have an important impact on the hypothalamic-pituitary-adrenal axis and in increased secretion of stress-related hormones, and may also be an aggravating factor for acne. ${ }^{21}$ Goulden et $a l^{3}$ and Poli et $a l^{35}$ reported stress as a worsening factor for acne in $71 \%$ and $50 \%$ of women, respectively.

Tobacco

There is a close relationship between smoking and the occurrence of AFA. ${ }^{36}$ Studies show that tobacco is the main factor responsible for the appearance of non-inflammatory acne in this age group, with a significant difference between female smokers and nonsmokers. The comedonal form predominates in smokers and is characterized by the presence of micro and macro-comedones and few inflammatory lesions, which led the authors to describe this clinical form as "smoker's face." The sebaceous gland is sensitive to acetylcholine that is stimulated by nicotine. Acetylcholine leads to cellular modulation and differentiation, inducing hyper-keratinization and influencing sebum production and composition, as well as reducing antioxidant agents and increasing peroxidation of sebum components, such as squalene. ${ }^{36}$

\section{Endocrine diseases}

The association of acne with an endocrinopathy characterized by hyper-androgenism usually presents other clinical signs such as: hirsutism, seborrhoea, alopecia, menstrual disorders, ovulatory dysfunction, infertility, early puberty, metabolic syndrome and virilization. ${ }^{37}$ The main endocrinopathies that occur with hyper-androgenism are: Polycystic ovary syndrome POS, late congenital adrenal hyperplasia or disfunction and, more rarely, ovarian, adrenal, pituitary and hypothalamic tumors. ${ }^{37}$

Hyperinsulinemia and peripheral insulin resistance occur frequently in women with POS. Hyperinsulinemia influences the concentration of plasma IGF-1 and Insulin Growth Factor Binding Protein-Like 3 binding protein (IGFBP-3), which act directly on keratinocyte proliferation and apoptosis. In a hyperinsulinemic state, the rate of IGF-1 is elevated and IGFBP-3 is lowered, leading to an imbalance that culminates in hyperproliferation of keratinocytes. Increased IGF-1 also inhibits aromatase and prevents the conversion of testosterone to estrogen. In this hyperinsulinemia, there is still a decrease in the hepatic production of SHBG, favoring the elevation of the free androgens that constitute its active form. ${ }^{37} \mathrm{In}$ adult women with acne and POS, it is important to evaluate the possibility of glucose intolerance. In POS, total cholesterol is increased at the expense of increasing the low density lipoprotein (LDL) fraction and decreasing the high density lipoprotein (HDL). Triglycerides 
are also increased as the plasminogen activator inhibitor (PAI) is. These changes in lipids and the increase in PAI favor arterial hypertension, coronary disease and thrombosis. ${ }^{37}$ In women with acne, obesity and PCOS, metabolic syndrome is very common, characterized by: 1 ) abdominal obesity (circumference of the waist) $>88 \mathrm{~cm} ; 2$ ) triglycerides> 150mg / dL; 3) $\mathrm{HDL}<50 \mathrm{mg} / \mathrm{dL}$; 4) blood pressure> 130 / > 85mm Hg; 5) high glycemia $=110-126 \mathrm{mg} / \mathrm{dL}$; and glycemia two hours after the glucose tolerance test $=140-199 \mathrm{mg} / \mathrm{dL} \cdot{ }^{37}$

\section{LABORATORY INVESTIGATIONS}

In the presence of other clinical signs of hyperandrogenism, most authors suggest plasma concentrations of free and total testosterone, S-DHEA, Luteinizing Hormone (LH), Follicle Stimulating Hormone (FSH) and, in some cases, when suspecting POS, transvaginal ultrasound for visualization of the ovaries. These dosages should always be performed in the follicular phase, preferably between the first and fifth day of the menstrual cycle and the collection should be done in the morning, between 8 and $10 \mathrm{am}$. In this way, the hormonal variations of the menstrual cycle interfere less with blood analysis. POS is the most frequently diagnosed cause. It is not recommended to perform exams when hormonal contraceptives are in use. ${ }^{37}$

In suspected POS, the following criteria should be checked: presence of menstrual alterations (amenorrhea or oligomenorrhea), clinical and/or biochemical and/or hyperandrogenism, as well as ultrasonographic changes (presence of 12 or more follicles with 2 and $9 \mathrm{~mm}$ of diameter or increase in ovarian volume $>10 \mathrm{~cm}^{3}$ ). In the revised consensus of 2004, the presence of two of the three criteria confirmed the diagnosis. ${ }^{38}$ However, today the difficulty persists for the standardization of the criteria for its precise diagnosis. ${ }^{39,40}$ Figure 2 presents a scheme for laboratory investigation of AFA.

Although most AFA patients show no signs of clinical or laboratory hyperandrogenism, slightly elevated levels of S-DHEA have been observed. ${ }^{41}$

DHT could be useful as a primary marker of peripheral androgen production, but its dosage is not recommended in clinical practice, since it is rapidly metabolized and has high affinity for SHBG. ${ }^{42}$

A distal metabolite of DHT, produced in androgen-responsive tissues, is 3 -alpha, 17 -beta-androstanediol glucuronate. In the final phase of metabolization, the enzyme $3 \alpha$-hydroxy dehydrogenase converts DHT to $3 \alpha$-androstenediol which undergoes glucuronidation. This modification decreases its affinity for binding proteins, increases its hydrophilicity and facilitates renal excretion. ${ }^{43}$ This metabolite can be used as a marker of hyperandrogenism, especially in women with idiopathic hirsutism, but is not useful in AFA.

Another androgenic metabolite of interest is Androsterone Glucuronate (ADT-G), which corresponds to $93 \%$ of all metabolites Currently the use of sensitive and specific laboratory techniques, such as liquid chromatography associated with mass spectrometry, for the dosages of this metabolite, allows evaluation of the total androgenic activity of the organism, with great accuracy, showing correlation with the clinical findings. ${ }^{44}$

\section{TREATMENT OF ADULT FEMALE ACNE}

AFA is a therapeutic challenge because it presents a tendency to relapse, even after cycles of oral antibiotics or isotretinoin. ${ }^{3}$ The typical evolution of AFA, with frequent relapses, makes maintenance treatment essential. ${ }^{45}$

In choosing the treatment, numerous factors must be taken into account: acne severity, response to previous treatments, psychosocial impact, possibility of pregnancy, slow response to treatment and increased risk of sensitive skin irritation. Individual preferences and costs are also important factors. ${ }^{2,7}$ In the Brazilian population, the diversity of phototypes, with a large contingent of patients prone to post-inflammatory hyperchromia, as well as climatic variation limit therapeutic options, contributing to their complexity. Figure 3 presents an algorithm for treating AFA.

\section{TOPICAL TREATMENT}

Topical treatments are the most widely used and effective option for treating moderate AFA and for maintenance treatment. Tolerability and efficacy may contribute to greater adherence to treatment, good outcomes, and patient satisfaction. ${ }^{46}$ Therapeutic regimens employing resources directed against two or more fundamental pathogenic factors are the main strategy in cases of mild to moderate intensity of acne. ${ }^{47}$

\section{Retinoids}

Adapalene: The efficacy and tolerability of adapalene $0.3 \%$ compared to the vehicle in women aged 18-41 was evaluated in an analysis of data obtained in two studies. There was a significant reduction at the $12^{\text {th }}$ week $(\mathrm{P}=0.045)$ of the inflammatory lesions (-61\%) and non-inflammatory lesions (-51\%). The main side effects were dryness and "skin discomfort". ${ }^{48}$ The concentration of $0.1 \%$ has also been studied with positive results and good tolerance. ${ }^{49}$

Tretinoin: Increased efficacy of AFA treatment was demonstrated when tretinoin at $0.025 \%$ concentration was associated with spironolactone. In that same study, another group used $0.1 \%$ adapalene in cream associated with spironolactone with similar results. Other authors have shown improvement in inflammatory acne in adolescents and adults when using topical tretinoin at concentrations of $0.04 \%$ to $0.1 \%$ in micro-capsulated presentations. ${ }^{50}$

\section{Antibiotics}

Topical antibiotics have a direct anti-inflammatory action reducing perifollicular lymphocytic infiltrate. Due to the significant increase of $P$. acnes strains resistant to clindamycin and erythromycin, the use of these substances alone is contra-indicated.?

\section{Benzoyl peroxide}

In adult women, benzoyl peroxide can induce irritative contact dermatitis or skin dryness, the extent of which is related to the amount and type of product, concentration, and vehicle. Therefore, concentrations of benzoyl peroxide above $5 \%$ are not recommended for use in adult women. ${ }^{7}$ It can also cause photosensitivity and bleaching of clothing.

\section{Azelaic acid}

Azelaic acid $20 \%$, applied twice a day, was evaluated in a study for the treatment of AFA in 241 women, alone or in combination with various treatments (including adapalene, benzoyl peroxide, cosmeceuticals, isotretinoin and oral hormonal contraceptives). The study concluded that topical treatment improved the Dermatol- 


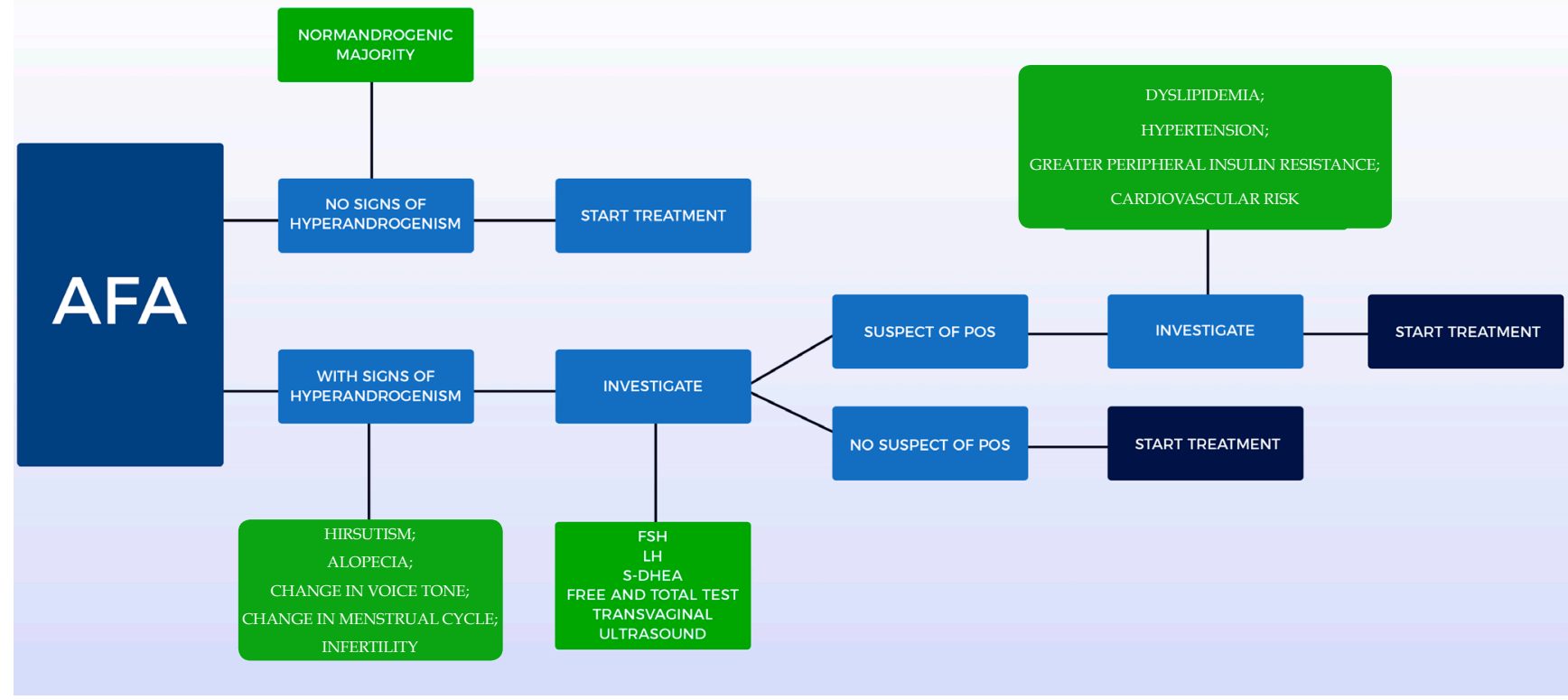

FigURE 2: Laboratory investigation of adult female acne (AFA)

TEST $=$ Testosterone $/$ POS = Polycystic Ovary Syndrome $/$ FSH = Follicle Stimulating Hormone $/$ LH = Luteinizing Hormone $/$ S-DHEA = Dehydroepiandrosterone Sulfate Source: Scheme developed by the authors

ogy Quality of Life Index (DLQI) and reduced the severity of acne. ${ }^{51}$ Azelaic Acid 15\% gel, applied twice daily, was also effective in reducing post-inflammatory pigmentation..$^{52}$ There was a significant reduction in the expression of TLR-2 in the skin of adult females with facial acne who used azelaic acid $15 \%$ gel or combined oral contraceptive (drospirenone + ethinylestradiol). The authors suggested a possible anti-inflammatory effect of oral contraceptive and azelaic acid in AFA via modulation of this receptor. ${ }^{53}$

According to the AFA review, published in 2013, azelaic acid $(20 \%$ cream or $15 \%$ gel) is recommended as the first line of treatment in monotherapy for non-inflammatory and inflammatory acne. Azelaic acid shows similar efficacy to other topical therapies in the treatment of mild to moderate acne and is associated with a favorable tolerability profile and high rates of satisfaction. ${ }^{7}$ Finally, it is unlikely that systemic side effects occur with azelaic acid, making it safe for use during pregnancy and breastfeeding. ${ }^{7}$ Azelaic acid represents an important option for women of childbearing age and with a desire to become pregnant as it is considered safe by the Food and Drug Administration (FDA).

\section{Dapsone}

Dapsone 5\% gel was used as treatment twice daily in black adult females with good efficacy and tolerance. In patients with acne vulgaris, it has been shown to be useful when combined with doxycycline and then alone as maintenance for long periods, with the advantage of having no risk for bacterial resistance. ${ }^{54,55}$

\section{Associations}

\section{Retinoids + Benzoyl peroxide}

The efficacy and safety of adapalene $0.1 \%$ combined with $2.5 \%$ benzoyl peroxide gel compared to the vehicle in women 25 years of age or older were analyzed by meta-analysis of data ex- tracted from subgroups from three multi-center, phase 2 and 3, randomized, parallel and double-blind studies. A rapid onset of action was demonstrated, with a significant reduction in lesions from the first week of use; the combination was considered effective, safe and tolerated well in both the population under 18 years and over 25 years, with similar indices. ${ }^{46}$

\section{Retinoids + Antibiotics}

The tretinoin-clindamicyn combination has been studied for the treatment of acne; a later analysis included only data from adult females. The combination proved to be more effective in reducing inflammatory and non-inflammatory lesions than the isolated tretinoin or clindamycin or the carrier substance. ${ }^{56}$

\section{Antibiotics + Benzoyl peroxide}

The combination of benzoyl peroxide $3.75 \%+$ clindamycin $1.2 \%$ was studied for long-term use (up to 24 weeks) in 20 adult females. At week 12, inflammatory lesions decreased by $70 \%$ and non-inflammatory lesions decreased by $58 \%$. In the $24^{\text {th }}$ week, the improvement was $93 \%$ and $90 \%$, respectively. There were no serious adverse events. This study allowed to evaluate the safety of longterm use as well as demonstrated continuous improvement. ${ }^{57}$

\section{SYSTEMIC TREATMENT}

\section{Antibiotics}

Adult women with facial acne have a good response to antibiotics; however, relapses are common after discontinuation of treatment. The combination of systemic antibiotics with topical products is recommended because it presents synergistic effects, accelerating the response and reducing the duration of treatment. Tetracycline and its derivatives are the first choice of antibiotics for the treatment of AFA. Second-generation tetracyclins, such as lymecycline, doxycycline and minocycline, are associated with better absorption when 

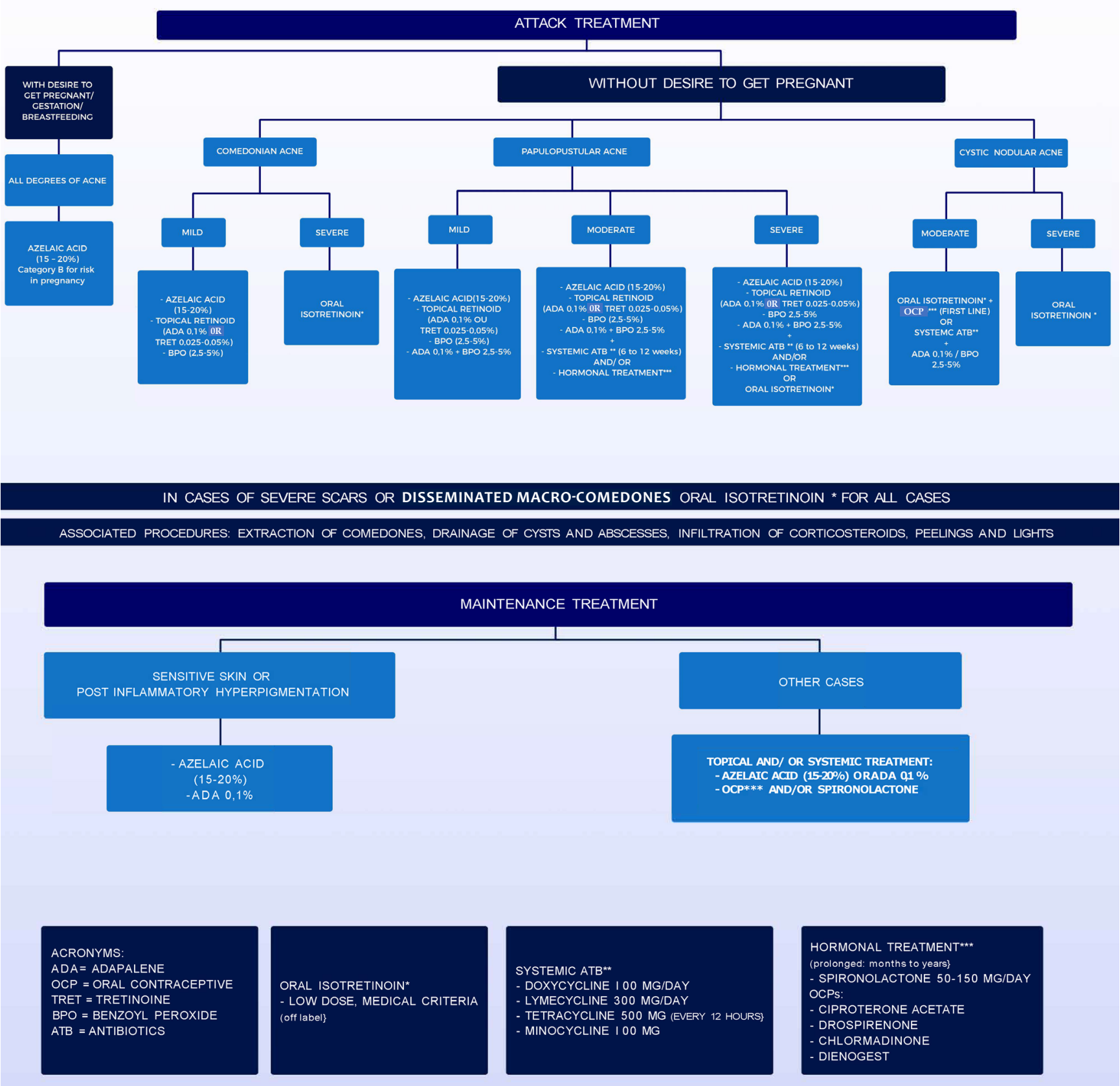

FigURE 3: Treatment algorithm of adult female acne Source: Developed By The Authors

ingested with food and better adherence, because of their single daily dose regimen. It should be emphasized that they should not be used during pregnancy as they may cause inhibition of skeletal fetal growth and dental changes. Erythromycin in stearate form can be used during pregnancy and lactation. ${ }^{7,58}$

Systemic antibiotics should not be used as monotherapy in the treatment of acne for the potential of developing bacterial resistance. Benzoyl peroxide in the concentration of 2.5 to $5 \%$ has syner- gistic action to antibiotics, accelerating the response, besides avoiding the development of resistance. Azelaic acid as well as topical retinoids are alternatives, particularly if there is hyperchromia. ${ }^{7,58}$

\section{Hormones}

Hormones are highly effective for AFA, even in patients without serum hormone changes, they are suitable for long-term therapy because they have no potential to induce bacterial resistance and represent an alternative to systemic antibiotics. In adult 
females, hormonal agents are recommended in the following situations: presence of severe seborrhea; worsening in the premenstrual period; presence of endocrine changes; persistent recalcitrant inflammatory acne in which standard treatments have failed, including repeated cycles of isotretinoin and when oral contraception is required or desired. As hormone treatments reduce excess sebum production, it is recommended that they are combined with agents that act on other pathogenic factors, such as antibiotics, benzoyl peroxide, retinoids, and azelaic acid. ${ }^{7,58}$

\section{Androgen receptor blockers}

The most prominent are: cyproterone acetate, spironolactone, drospirenone and flutamide.

Ciproterone acetate: Combined with ethinylestradiol, it is recommended for the treatment of mild to moderate AFA. Side effects include menstrual changes, tenderness and enlargement of the breast, nausea, vomiting, fluid retention, edema, headache, and melasma. ${ }^{7}$

SPIRONOLACTONE: A study published by Sato et al ${ }^{59}$, demonstrated efficacy of spironolactone in the treatment of adult females with acne vulgaris. In monotherapy, $80 \%$ of the patients present menstrual irregularity. ${ }^{59}$ A retrospective study of spironolactone found that there is no need for periodic control of potassium levels in young women, who do not have nephropathies, and are not users of other medications that may increase potassium levels. ${ }^{60}$ The combined use of spironolactone with topical retinoid seems to provide a superior response to the retinoid treatment isolated in AFA ${ }^{61}$ Spironolactone can be used to promote androgen blockade in patients using levonorgestrel intrauterine devices or to increase androgen blockade in those who opt for combined oral contraceptive pills (OCPs) ${ }^{62}$ In these cases, doses of $100 \mathrm{mg}$ daily are safe and rarely associated with side effects. ${ }^{63}$ A systematic review published in 2017 concluded that the evidence for its use in the treatment of AFA is still poor, its recommendation is still based on expert opinion or consensus, and randomized, controlled, double-blind trials for the proof of effectiveness are still lacking. ${ }^{64}$

Inhibitors of ovarian androgen production

OCPs containing ethinyl estradiol combined with progestins with antiandrogenic activity are recommended for the treatment of mild to moderate AFA. Although the evidence is limited and somewhat conflicting, combinations containing cyproterone acetate may be slightly more effective than those containing newer progestins, such as desogestrel, gestodene, levonorgestrel, or norgestimate. Drospirenone-containing OCPs are effective in reducing inflammatory and non-inflammatory acne lesions. Clinicians should be aware of the absolute and relative contra-indications of OCPs prior to prescription. ${ }^{7}$ According to a systematic review in 2014, the risk of thromboembolism with OCPs is related to both estrogen and progestin type. Thus, the higher the estrogen concentration the greater the risk, and for the progestins it was concluded that the second generation (more androgenic) have a lower risk than those of the third and fourth generations. ${ }^{65}$

Inhibitors of adrenal androgen production

Low doses of corticosteroids, such as prednisone (2.5 or $5 \mathrm{mg}$ ), can suppress adrenal androgen production and are recommended in late congenital adrenal hyperplasia, acute inflammatory lesions in AFA, and short-term treatment of very severe acne. ${ }^{7}$

\section{Isotretinoin}

Except for severe cases, oral isotretinoin is typically indicated only after failure of conventional treatments. In adult females it may be recommended, with great attention to the elevated risk of teratogenicity, making the adoption of highly effective contraception methods mandatory. If there are no contra-indications, it is the first line for nodulocystic acne and second line for moderate forms not responsive to courses of oral antibiotic always associated with topical medications and frequent recurrences, tendency to scars and negative psychosocial impact. ${ }^{66,67}$

It acts by reducing the size and activity of the sebaceous glands by apoptosis of sebocytes; exhibits anti-inflammatory properties by modulating TLR 2 expression and gene transcription mediated by Fox O or Forkhead Box Class O. ${ }^{68,69}$ Due to the multiple mechanisms of action, several off-label indications have already been suggested in the literature such as AFA, rosacea, photo-aging, seborrheic dermatitis, among others. ${ }^{70-74}$

Its effectiveness is undeniable, but there are side effects. The most common are mucocutaneous: cheilitis, xerophthalmia, conjunctivitis, nasal dryness, epistaxis and irritative dermatitis. Laboratory abnormalities may include elevation of liver enzymes, increase in triglyceride and cholesterol levels, elevation of LDL fraction, and decrease in HDL fraction. ${ }^{75-78}$ Teratogenicity is the most serious and irreversible adverse effect. Fetal exposure to isotretinoin, regardless of dose, at any time during gestation, but especially in the first trimester, can cause serious defects, with an incidence of approximately $28 \%{ }^{79}$

The occurrence of depression, suicidal ideation or attempted suicide associated with isotretinoin in the treatment of acne vulgaris has been reported in the literature of case reports and case-control studies. The observed incidence ranges from less than $1 \%$ to $3 \%$, while in the general population it is estimated to be between 1.6 and $7.5 \%$, with an average of $3 \%{ }^{80}$ Numerous studies have concluded that the drug more often determines improvement or cure of depressive symptoms that have been proven to be related to acne and cause depression. ${ }^{81,82}$ Population studies have not confirmed this association. However, the recommendation remains to monitor symptoms and, if necessary, request psychiatric evaluation and treatment. It is worth remembering that in adult females, emotional and psychic disorders, stress, insomnia, and other symptoms are common. ${ }^{21}$

The development of Inflammatory Bowel Disease (IBD), particularly ulcerative colitis was related to isotretinoin. However, several population-based, case-control studies have concluded that this association does not exist. ${ }^{83,84}$ On the other hand, Crohn's disease has been reported with the use of tetracycline-class antibiotics, particularly doxycycline and even topical treatments for acne, evidencing that the causal factor is the disease and not the therapeutic option..$^{85}$ There seems to be a misconception about the true triggering factor. A recent meta-analysis has shown that there is no increased risk of developing IBD after exposure to isotretinoin. ${ }^{86}$

Clinical and laboratory monitoring includes detailed history, complete physical examination, and complementary examinations. Reassessments of hepatic lipids and transaminases were performed monthly in the past. Considering that the proportion of patients with laboratory abnormalities is low, particularly adoles- 
cents, it is currently recommended to repeat the tests 4 to 6 weeks after starting treatment and reassessments only for those who have changed. ${ }^{86-88}$ The recommended daily dose is 0.5 to $1.0 \mathrm{mg} / \mathrm{kg}$, after meals (preferably fatty), for a period of 6 to 12 months, up to a total dose of 120 to $150 \mathrm{mg} / \mathrm{kg}{ }^{66,67}$

There are reports of use of lower daily doses, without the need to reach the total dose of $120 \mathrm{mg} / \mathrm{kg}$ body weight. The benefits of regimens with 0.3 to $0.4 \mathrm{mg} / \mathrm{kg} /$ day, $20 \mathrm{mg} /$ day, $20 \mathrm{mg}$ every other day, $5 \mathrm{mg} /$ day, in the treatment of moderate acne, with the same efficacy, fewer side effects and greater adherence to treatment. ${ }^{89-91}$ However, this is not recommended for use in leaflets. These regimens may be a useful option for AFA resistant to topical and hormonal treatments by reducing adverse events. However, effective prevention of pregnancy is necessary since these women may be of childbearing age and the risk of teratogenicity is equal to the use at usual doses. ${ }^{79}$ To begin treatment in women of childbearing age, it is necessary to inform of the risks, the need for two contraceptive methods, pregnancy tests and to wait for menstruation. In adult females, particularly those with overweight tendency or obese, or with hormonal changes, more frequent laboratory monitoring becomes essential. There has been an increased risk of elevated cholesterol and triglycerides and weight gain..$^{92,93}$ No changes were detected in serum androgens and insulin. ${ }^{93}$

Adult women with hyperandrogenism often require more than one course of treatment with isotretinoin, in addition to hormones. One measure that may contribute to avoid recurrence is maintenance therapy with adapalene, benzoyl peroxide, or azelaic acid for 6 months to 2 years. ${ }^{94} \mathrm{~A}$ risk of relapse that is 3.5 times greater has been reported in women who did not use concomitant anti-androgen therapy. ${ }^{95}$

\section{Adjuvant treatments}

\section{Cosmeceuticals and cosmetics}

The topical and systemic treatment for acne can cause dryness, irritation, damage to the epidermal barrier, increased transepidermal water loss and inflammation, and may reduce adhesion. Moisturizers may contribute to reduce these adverse events of topical products and oral isotretinoin by avoiding the impairment of the epidermal barrier that is essential to prevent or reduce inflammation. ${ }^{7,96,97}$

Many authors consider that because cosmeceuticals are available without prescription and medical supervision, there may be harm in educating patients about their dermatoses (such as acne). Intensive advertising is highly targeted at adult females and may induce them to self-medication with ineffective and skin-irritating products, as well as causing delay in seeking suitable dermatological care, increasing the risk of continuation. In addition, data on acne efficacy is limited and information presented by companies is much more based on in vitro research than in randomized controlled trials of finished products. ${ }^{98}$

Acne cosmeceuticals include cleansing agents for oily or sensitive skin, sebaceous secretion regulators, anti-inflammatory drugs, moisturizers and sunscreens (useful for preventing post-inflammatory hyperpigmentation). Clinical data on retinoids retinol, retinaldehyde, retinyl ester, adapalene $0.1 \%$, niacinamide (active form, amide, niacin or nicotinic acid or vitamin B3) and glycolic acid in concentrations of 5 to $20 \%$ indicate that they may be useful in the initial, mild to moderate forms of acne, particularly comedonal and accompanied by increased seborrhea. They are not superior to medicines for these forms and there is no data for severe acne. ${ }^{99} \mathrm{Nia}-$ cinamide may be useful for antimicrobial, sebostatic, anti-inflammatory effects, inhibition of melanosome transfer, increased synthesis of ceramides, inhibition of nitric oxide and consequent changes in capillary permeability. ${ }^{100}$

As some anti-acne agents may cause skin dryness, erythema and discomfort, moisturizers and cleansing agents (preferably soapfree and near-skin $\mathrm{pH}$ ) are recommended as an essential part of the therapeutic regimen in AFA. ${ }^{7}$ It is necessary to add photo-protection with non-comedogenic products capable of also providing comfort and hydration. In certain climatic conditions the use of moisturizer may be crucial for adherence to treatment, counteracting dryness and improving the barrier function of the stratum corneum. ${ }^{97}$

Glycolic acid is the alpha-hydroxy acid most used in the treatment of acne and hyperpigmentation, as it quickly crosses the stratum corneum, reaches the lower layers of the epidermis and the hair follicles reducing the cohesion between the keratinocytes. It is considered useful in reducing the size of follicular ostia and in removing comedones. ${ }^{101} \mathrm{~A}$ topical combination containing $10.4 \%$ L-lactic acid, 2\% salicylic acid and alpha-hydroxy acid/retinoate conjugate (ethyl lactyl retinoate) was used in the topical treatment of females of ages 20 to 58 . After 4 weeks, improvement was achieved, which remained continuous and cumulative in the eighth week. ${ }^{102}$

A formulation containing $0.1 \%$ retinaldehyde and $6 \%$ glycolic acid was studied for concomitant use with other acne treatments (except retinoids) and has been shown to be tolerable. Authors commented on the possibility of using this formulation as monotherapy in mild to moderate acne. ${ }^{103}$

Among cosmetics, corrective makeup and camouflage are useful and should be part of the therapeutic regimen as they improve the quality of life, contribute to sun protection and reduce the habit of inconsistency, very common in females. Obvious facial injuries are a very important problem for women. Well-targeted use of cosmeceuticals and cosmetics can benefit drug treatment by reducing side effects, reducing the need for topical antibiotics, and improving adherence to the therapeutic regimen..$^{97,104}$

\section{Mechanical procedures}

Intralesional infiltration with corticosteroid: The corticosteroid of choice for this minimally invasive procedure is triamcinolone acetonide. It is indicated in nodulocystic acne, in a concentration of $2.5 \mathrm{mg} / \mathrm{mL}$, diluted in distilled water, in single application, with improvement in 48 to 72 hours. In the presence of multiple lesions, $5 \mathrm{mg}$ per application should not be exceeded to avoid systemic absorption. ${ }^{105}$ It is useful in the treatment of inflammatory nodules, even during the use of oral isotretinoin, since it accelerates regression and relieves pain rapidly in these lesions. It is also indicated in the approach of hypertrophic and keloid scars, with total or partial regression. ${ }^{66,106}$

Manual extraction of comedones: Removal of comedones, particularly open ones, may be useful by unclogging the follicular opening, facilitating the penetration of topical keratolytic products and contributing to the reduction of inflammation. In addition, it 
provides a positive impact on the quality of life, prevents the manipulation of the lesions in an inadequate way by the patient and/ or laymen. ${ }^{66}$

Eletrocauterization of macro-comedones: The electrocautery of closed macro-comedones should be performed with great care not to reach excessive depth and cause scarring. It is useful since macro-comedones frequently evolve to inflammatory lesions. In addition, it avoids manipulation that causes exulcerations and inflammation. ${ }^{66}$

Draining of cysts and abscesses: It is a necessary procedure when there is fluctuation in these lesions, associated with the use of oral antibiotics, because it reduces the period of evolution and the scarring development.

Microdermabrasion: Microdermabrasion is a very superficial exfoliation method equivalent to a superficial peeling. It is based on the blasting of aluminum crystals until the appearance of mild erythema. After 2 to 3 days there is a fine peeling. The advantage over chemical peels is lack of burning, but the result may be poorer. It is most indicated in the preparation of the skin for the treatment of superficial atrophic scars. It is a simple, safe procedure and when carried out serially in several weekly sessions can induce reorganization and increase the density of dermal collagen. ${ }^{66,107}$

\section{Chemical peels, lights and lasers}

The superficial chemical peels have keratolytic action, causing superficial exfoliation due to its epidermal effects that are useful for comedonal and mild inflammatory forms. The most commonly used agents in the treatment of active acne are Jessner's solution, $10 \%$ trichloroacetic acid (TCA) or $20 \%$ in aqueous solution, $30 \%$ salicylic in hydro-alcoholic solution or polyethylene glycol, $70 \%$ glycolic or other gel concentrations of natrosol, with partially buffered $\mathrm{pH}$ and $50 \%$ pyruvic acid. Salicylic and pyruvic acids have demonstrated a significant reduction in sebum content in the skin with acne through sebummetry. ${ }^{108}$ Several comparative studies have shown similar efficacy among the agents, with varying differences in tolerability. ${ }^{109}$ All can cause burning, erythema and desquamation after 3 to 5 days, lasting from 7 to 15 days. Unpredictable immediate reactions may occur, particularly with glycolic acid, which requires more care and observation of symptoms and signs until their removal. Such reactions include edema, vesiculation and undesirable bleaching due to epidermolysis. In this situation, immediate neutralization with $10 \%$ sodium bicarbonate in aqueous solution and removal of the agent should be performed. In general, they are safe procedures, without late complications; except when exaggerated, unpredictable immediate reactions occur that may cause post-inflammatory hyperpigmentation.

The average peels are performed with the combination of a keratolytic agent - Jessner's solution (no removal) or 70\% glycolic acid (removed as soon as there is mild burning or the appearance of erythema) - and TCA 35\% in aqueous solution applied immediately after. They are indicated for the treatment of superficial atrophic scars in isolated semi-annual applications or associated with other procedures at different times, particularly when they are deep. ${ }^{106,110,111}$ In this situation, the peel acts as a preparation of the skin, making its surface more homogeneous.

The application of blue or red light emitting diodes (LEDs) has an anti-inflammatory effect faster than topical and/or systemic treatments. One study showed that this effect was similar to salicylic acid peel. The associated lights in the early stages of treatment improved inflammation and adhesion. No adverse event has been recorded. ${ }^{112}$ Photodynamic Therapy (PDT), as it is better known, has been proposed as a therapeutic option for acne, although with many doubts and scanty evidence. ${ }^{113}$

A review of randomized, controlled studies of light-based therapies for acne treatment concluded that none of the studies demonstrated efficacy; it is necessary to carry out well-designed studies that employ standardized outcome measures as well as comparison with usual drug treatments. ${ }^{114}$

At the moment there is no laser technology whose target is the sebaceous gland and that can destroy it, leading to healing. Two suggestions have been discussed. One associates an integrated cooling and vacuum system applied to the skin followed by the application of 3 to 4 pulses of the 1540-nm medium-erbium: glass infrared laser. An open, uncontrolled study including 12 patients with mild to moderate acne used this method in 4 to 6 sessions, with a 2-week interval. The improvement scores were 3.6 and 2.0, on a scale of 0 to 4 , after one and 3 months of the last session, without adverse events. ${ }^{115}$ Another recently developed method is the use of a suspension of inert gold micro-particles with silica center applied with 8 -minute massage on the face followed by $800 \mathrm{~nm}$ laser application. There are 3 sessions, with intervals of 2 weeks. There are reports of improvement of up to $61 \%$ of inflammatory lesions. ${ }^{116}$

\section{Scars}

Acute atrophic acne scars can be treated with minimally invasive procedures such as medium chemical peels, hyaluronic acid and L-poly-lactic acid fillers, and non-ablative radiofrequency. ${ }^{117}$ The most severe, which may be persistent, have a negative impact on the quality of life and pose a therapeutic challenge. The treatment is always prolonged and requires an association of techniques, including surgical removal of areas with intense atrophy, in several sessions. ${ }^{117-119}$ The most invasive procedures include: sub-incision, punch lift, dermabrasion, fractional $\mathrm{CO}_{2}$ laser or Erbium: Yag, ablative or non-ablative, microneedling, and radiofrequency, among others. The most commonly mentioned are the medium peels, various types of lasers and, more recently, microneedling. ${ }^{109,118-121}$ Studies with histological evaluation after fractionated $\mathrm{CO}_{2}$ laser treatment showed thickening of the epidermis, disappearance of degenerated elastic fibers, increased elastic fiber density and dermal collagen. ${ }^{119,120}$ These effects, in addition to treating scars, improve the general appearance of the skin and the signs of photo-aging, constituting interesting results for adult females. The combination of techniques is the most effective option for acne scars. A retrospective, non-blind, uncontrolled study evaluated in 114 patients the results of the combination, under tumescent anesthesia, in a single session, of $20 \%$ TCA superficial peel, extensive sub-incision and fractionated $\mathrm{CO}_{2}$ laser. There was improvement of 2.9 on a scale of 1 to 4 and few complications; $90 \%$ of the patients were satisfied. ${ }^{122}$ A recent systematic review concluded that there is no evidence of high quality for the various interventions proposed for the treatment of acne scars due to poor methodology, lack of statistical power, lack of standardization of efficacy data and variables evaluated before the interven- 
tions. There is moderate evidence for fillers, but there is a lack of studies with prolonged follow-up (the largest was 48 weeks) and comparative with placebo or false intervention. This review was not able to establish any intervention as a first line for the treatment of acne scars. ${ }^{123}$

\section{Maintenance treatment}

Maintenance therapy is needed to minimize the likelihood of relapse after treatment, since acne recurrences are common. Factors such as efficacy, tolerability and adherence should be taken into account when assessing the duration of maintenance therapy. According to an European review, 15 or $20 \%$ azelaic acid, $0.025 \%$ or $0.05 \%$ tretinoin and $0.1 \%$ adapalene are recommended as maintenance therapy in AFA. ${ }^{7}$

\section{QUALITY OF LIFE}

The term quality of life (QoL) can be characterized, in a subjective way, as the patient's perception about their illness and treatment, whereas in the technical concept it covers a series of components related to mental health, physical, functional and social dimensions. In dermatological diseases, studies suggest that psychometric tools may help the physician better choose the therapeutic proposal and detect patients psychologically affected, even with a clinical condition considered to be mild. The development of indicators, instruments or questionnaires is based on evidence that there is disagreement between the evaluation of the physician or health professional and that of the patient regarding the severity of the disease and treatment success, as well as different responses to the established therapy and different levels of satisfaction between patients with the same clinical condition. ${ }^{124}$
Studies related to acne point to a negative influence on quality of life, including the presence of signs and symptoms of depression and anxiety, such as anger and low self-esteem. ${ }^{125-127}$ The use of disease-specific questionnaires, such as Quality of Life in Acne (Acne-QoL), already translated and validated for Brazilian Portuguese, quantifies the impact of acne on quality of life. ${ }^{128-130}$

The literature shows that the impact on quality of life does not always correlate with the severity of acne. In some cases, females with mild clinical conditions have a high impact on quality of life. ${ }^{126}$ Studies have also shown that the psychological impact of acne appears to affect more females than males. ${ }^{131}$ In any case, the physician's attention, good relationship with the patient and adequate treatment, topical and/or systemic, although not completely effective demonstrates a positive impact on quality of life. ${ }^{53}$

\section{CONCLUSION}

AFA has been considered a particular subtype of acne, distinct from acne vulgaris or adolescent acne, not only for differences in clinical status and etiopathogenesis, but also for its chronicity, which may last until the postmenopausal period. Some characteristics such as more sensitive and less oily skin, and multiple etiopathogenic factors, such as new work rate in women's lives, stress, sleep disorders, dietary supplements and certain types of contraceptive methods make management more complex. Recent findings on its chronicity, involving TLR stimulation, demonstrate that control of the innate immune response has contributed to understanding the mechanism of action of the drugs used in its treatment.

For all these issues, AFA is a challenge in clinical practices and should be further understood.

\section{ERRATUM}

In the manuscript "Adult female acne: a guide to clinical practice", with DOI: http://dx.doi.org/10.1590/abd18064841.20198203, published in the Anais Brasileiros de Dermatologia, 2019;94(1):62-75., in the pages 62-75.

\section{Where it reads:}

Maria Cecilia Rivitti Machado

It should read:

Maria Cecília Rivitti-Machado 


\section{REFERENCES}

1. Dréno B, Thiboutot D, Layton AM, Berson D, Perez M, Kang S; Global Alliance to Improve Outcomes in Acne. Large-scale international study enhances understanding of an emerging acne population: adult females. J Eur Acad Dermatol Venereol. 2015;29:1096-106.

2. Dréno B. Treatment of adult female acne: a new challenge. J Eur Acad Dermatol Venereol. 2015;29(Suppl 5):14-9.

3. Goulden V, Clark SM, Cunliffe WJ. Post-adolescent acne: a review of clinical features. Br J Dermatol. 1997;136:66-70.

4. Tanghetti EA, Kawata AK, Daniels SR, Yeomans K, Burk CT, Callender VD. Understanding the burden of adult female acne. J Clin Aesthet Dermatol. 2014;7:22-30.

5. Cunliffe WJ, Gould DJ. Prevalence of facial acne vulgaris in late adolescence and in adults. Br Med J. 1979;1:1109-10.

6. Schmitt JV, Masuda PY, Miot HA. Acne in women: clinical patterns in different age-groups. An Bras Dermatol. 2009;84:349-54.

7. Dréno B, Layton A, Zouboulis CC, López-Estebaranz JL, Zalewska-Janowska A, Bagatin E, et al. Adult female acne: a new paradigm. J Eur Acad Dermatol Venereol. 2013;27:1063-70.

8. Preneau S, Dreno B. Female acne - a different subtype of teenager acne? J Eur Acad Dermatol Venereol. 2012;26:277-82.

9. Zeichner JA, Baldwin HE, Cook-Bolden FE, Eichenfield LF, Fallon-Friedlander S, Rodriguez DA. Emerging Issues in Adult Female Acne. J Clin Aesthet Dermatol. 2017:10:37-46.

10. Silpa-Archa N, Kohli I, Chaowattanapanit S, Lim HW, Hamzavi I. Postinflammatory hyperpigmentation: A comprehensive overview: Epidemiology, pathogenesis, clinical presentation, and noninvasive assessment technique. J Am Acad Dermatol. 2017:77:591-605.

11. Addor FA, Schalka S. Acne in adult women: epidemiological, diagnostic and therapeutic aspects. An Bras Dermatol. 2010;85:789-95.

12. Auffret N, Claudel JP, Leccia MT, Poli F, Farhi D, Dréno B. AFAST - Adult Female Acne Scoring Tool: an easy-to-use tool for scoring acne in adult females. J Eur Acad Dermatol Venereol. 2016;30:824-8.

13. Dréno B, Poli F, Pawin H, Beylot C, Faure M, Chivot M, et al. Development and evaluation of a Global Acne Severity Scale (GEA Scale) suitable for France and Europe. J Eur Acad Dermatol Venereol. 2011;25:43-8.

14. Bhat YJ, Latief I, Hassan I. Update on etiopathogenesis and treatment of Acne. Indian J Dermatol Venereol Leprol. 2017;83:298-306.

15. Antiga E, Verdelli A, Bonciani D, Bonciolini V, Caproni M, Fabbri P. Acne: a new modelo f imune-mediated chronic inflammatory skin disease. G Ital Dermatol Venereol. 2015;150:247-54.

16. Rocha MA, Costa CS, Bagatin E. Acne vulgaris: an inflammatory disease even before the onset of clinical lesions. Inflamm Allergy Drug Targets. 2014;13:162-7.

17. Del Rosso JQ, Harper JC, Graber EM, Thiboutot D, Silverberg NB, Eichenfield LF. Status report from the American Acne \& Rosacea Society on medical management of acne in adult women, part 2: topical therapies. Cutis. 2015;96:321-5.

18. Rocha MA, Bagatin E. Skin barrier and microbiome in acne. Arch Dermatol Res. 2018:310:181-5.

19. Goulden V, McGeown $\mathrm{CH}$, Cunliffe WJ. The familial risk of adult acne: a comparison between first-degree relatives of affected and unaffected individuals. Br J Dermatol. 1999;141:297-300.

20. Zouboulis CC, Picardo M, Ju Q, Kurokawa I, Töröcsik D, Bíró T. Beyond acne: Current aspects of sebaceous gland biology and function. Rev Endocr Metab Disord. 2016;17:319-34.

21. Albuquerque RG, Rocha MA, Bagatin E, Tufik S, Andersen ML. Could adult female acne be associated with modern life? Arch Dermatol Res. 2014;306:683-8.

22. Das S, Reynolds RV. Recent advances in acne pathogenesis: implications for therapy. Am J Clin Dermatol. 2014;15:479-88.

23. Beylot C, Auffret N, Poli F, Claudel JP, Leccia MT, Del Giudice P, et al. Propionibacterium acnes: an update on its role in the pathogenesis of acne. J Eur Acad Dermatol Venereol. 2014;28:271-8.

24. Ribeiro BM, Almeida LMC, Costa A, Francesconi F, Follador I, Neves JR. Etiopatogenia da acne vulgar: uma revisão prática para o dia a dia do consultório de dermatologia. Surg Cosmet Dermatol. 2015;7(Supl 1):S20-6.

25. Dreno B, Gollnick HP, Kang S, Thiboutot D, Bettoli V, Torres V, et al. Understanding innate immunity and inflammation in acne: implications for management. J Eur Acad Dermatol Venereol. 2015;29(Suppl 4):3-11

26. Melnik BC, Zouboulis CC. Potential role of Fox01 and mTORC1 in the pathogenesis of Western diet-induced acne. Exp Dermatol. 2013;22:311-5.

27. Pontes Tde C, Fernandes Filho GM, Trindade Ade S, Sobral Filho JF. Incidence of acne vulgaris in young adult users of protein-calorie supplements in the city of João Pessoa - PB. An Bras Dermatol. 2013;88:907-12.

28. Kazandjieva J, Tsankov N. Drug-induced acne. Clin Dermatol. 2017;35:156-62.

29. Dréno B. General antibiotic therapy in acne. Rev Prat. 2002;52:841-3.
30. Kang D, Shi B, Erfe MC, Craft N, Li H. Vitamin B12 modulates the transcriptome of the skin microbiota in acne pathogenesis. Sci Transl Med. 2015;7:293ra103.

31. Zeichner JA. Evaluating and treating the adult female patient with acne. J Drugs Dermatol. 2013;12:1416-27.

32. Lortscher D, Admani S, Satur N, Eichenfield LF. Hormonal Contraceptives and Acne: A Retrospective Analysis of 2147 Patients. J Drugs Dermatol. 2016;15:670-4.

33. Gezginc K, Balci 0, Karatayli R, Colakoglu MC. Contraceptive efficacy and side effects of Implanon. Eur J Contracept Reprod Health Care. 2007;12:362-5.

34. Bahamondes L, Brache V, Meirik 0, Ali M, Habib N, Landoulsi S; WHO Study Group on Contraceptive Implants for Women. A 3-year multicentre randomized controlled trial of etonogestrel- and levonorgestrel-releasing contraceptive implants, with non-randomized matched copper-intrauterine device controls. Hum Reprod. 2015;30:2527-38

35. Poli F, Dreno B, Verschoore M. An Epidemiological study of acne in female adults: results of a survey conducted in France. J Eur Acad Dermatol Venereol. 2001:15:541-5.

36. Yang YS, Lim HK, Hong KK, Shin MK, Lee JW, Lee SW, et al. Cigarette smokeinduced interleukin-1 alpha may be involved in the pathogenesis of adult acne. Ann Dermatol. 2014;26:11-6.

37. Yarak S, Bagatin E, Hassun KM, Parada MOAB, Talarico Filho S. Hyperandrogenism and skin: polycystic ovary syndrome and peripheral insulin resistance. An Bras Dermatol. 2005;80:395-410.

38. Rotterdam ESHRE/ASRM-Sponsored PCOS consensus workshop group. Revised 2003 consensus on diagnostic criteria and long-term health risks to polycystic ovary syndrome (PCOS). Hum Reprod. 2004;19:41-7.

39. Marcondes JA, Barcellos CR, Rocha MP. Difficulties and pitfalls in the diagnosis of polycystic ovary syndrome. Arq Bras Endocrinol Metabol. 2011:55:6-15.

40. Sirmans SM, Pate KA. Epidemiology, diagnosis, and management of polycystic ovary syndrome. Clin Epidemiol. 2013 Dec 18;6:1-13

41. Carmina E, Godwin AJ, Stanczyk FZ, Lippman JS, Lobo RA. The association of serum androsterone glucuronide with inflammatory lesions in women with adult acne. J Endocrinol Invest. 2002;25:765-8.

42. Cappel M, Mauger D, Thiboutot D. Correlation between serum levels of insulinlike growth factor 1, dehydroepiandrosterone sulfate, and dihydrotestosterone and acne lesion counts in adult women. Arch Dermatol. 2005:141:333-8.

43. Azzouni F, Godoy A, Li Y, Mohler J. The 5 alpha-reductase isozyme family: a review of basic biology and their role in human diseases. Adv Urol. 2012;2012:530121.

44. Labrie F, Luu-The V, Bélanger A, Lin SX, Simard J, Pelletier G, et al. J Is dehydroepiandrosterone a hormone? J Endocrinol. 2005;187:169-96.

45. Holzmann R, Shakery K. Postadolescent acne in females. Skin Pharmacol Physiol. 2014; 27 (Suppl 1):S3-8.

46. Gold LS, Baldwin H, Rueda MJ, Kerrouche N, DrÉno B. Adapalene-benzoyl Peroxide Gel is Efficacious and Safe in Adult Female Acne, with a Profile Comparable to that Seen in Teen-aged Females. J Clin Aesthet Dermatol. 2016;9:23-9.

47. Nast A, Dréno B, Bettoli V, Degitz K, Erdmann R, Finlay AY, et al. European evidence-based (S3) guidelines for the treatment of acne. J Eur Acad Dermatol Venereol. 2012;26(Suppl 1):S1-29.

48. Berson D, Alexis A. Adapalene $0.3 \%$ for the Treatment of Acne in Women. J Clin Aesthet Dermatol. 2013:6:32-5.

49. Thielitz A, Lux A, Wiede A, Kropf S, Papakonstantinou E, Gollnick H. A randomized investigator-blind parallel-group study to assess efficacy and safety of azelaic acid $15 \%$ gel vs. adapalene $0.1 \%$ gel in the treatment and maintenance treatment of female adult acne. J Eur Acad Dermatol Venereol. 2015;29:789-96.

50. Berger R, Rizer R, Barba A, Wilson D, Stewart D, Grossman R, et al. Tretinoin gel microspheres $0.04 \%$ versus $0.1 \%$ in adolescents and adults with mild to moderate acne vulgaris: a 12-week, multicenter, randomized, double-blind, parallel-group, phase IV trial. Clin Ther. 2007;29:1086-97.

51. Kainz JT, Berghammer G, Auer-Grumbach P, Lackner V, Perl-Convalexius S, Popa $\mathrm{R}$, et al. Azelaic acid $20 \%$ cream: effects on quality of life and disease severity in adult female acne patients. J Dtsch Dermatol Ges. 2016;14:1249-59.

52. Kircik LH. Efficacy and safety of azelaic acid (AzA) gel $15 \%$ in the treatment of post-inflammatory hyperpigmentation and acne: a 16-week, baseline-controlled study. J Drugs Dermatol. 2011;10:586-90.

53. Rocha MAD, Guadanhim LRS, Sanudo A, Bagatin E. Modulation of Toll Like Receptor-2 on sebaceous gland by the treatment of adult female acne. Dermatoendocrinol. 2017:9:e1361570.

54. Alexis AF, Burgess C, Callender VD, Herzog JL, Roberts WE, Schweiger ES, et al. The Efficacy and Safety of Topical Dapsone Gel, $5 \%$ for the Treatment of Acne Vulgaris in Adult Females With Skin of Color. J Drugs Dermatol. 2016;15:197-204.

55. Kircik LH. Use of Dapsone $5 \%$ Gel as Maintenance Treatment of Acne Vulgaris Following Completion of Oral Doxycycline and Dapsone 5\% Gel Combination Treatment. J Drugs Dermatol. 2016;15:191-5. 
56. Dréno B, Bettoli V, Ochsendorf F, Layton AM, Perez M, Dakovic R, et al. Efficacy and safety of clindamycin phosphate $1.2 \% /$ tretinoin $0.025 \%$ formulation for the treatment of acne vulgaris: pooled analysis of data from three randomised double-blind, parallel-group, phase III studies. Eur J Dermatol. 2014;24:201-9.

57. Kircik LH. Fixed Combination of Clindamycin Phosphate $1.2 \%$ and Benzoyl Peroxide 3.75\% Aqueous Gel: Long-Term Use in Adult Females With Moderate Acne Vulgaris. J Drugs Dermatol. 2017;16:543-6.

58. Bagatin E, Florez-White M, Arias-Gomez Ml, Kaminsky A. Algorithm for acne treatment - Iberian-Latin American Consensus. An Bras Dermatol. 2017;92:689-93.

59. Sato K, Matsumoto D, lizuka F, Aiba-Kojima E, Watanabe-Ono A, Suga H, et al. Anti-androgenic therapy using oral spironolactone for acne vulgaris in Asians. Aesthetic Plast Surg. 2006;30:689-94.

60. Plovanich M, Weng QY, Mostaghimi A. Low Usefulness of Potassium Monitoring Among Healthy Young Women Taking Spironolactone for Acne. JAMA Dermatol. 2015;151:941-4.

61. Lessner E, Fisher S, Kobraei K, Osleber M, Lessner R, Elliott L, et al. Spironolactone and topical retinoids in adult female cyclical acne. J Drugs Dermatol. 2014;13:126-9.

62. Kim GK, Del Rosso JQ. Oral Spironolactone in Post-teenage Female Patients with Acne Vulgaris: Practical Considerations for the Clinician Based on Current Data and Clinical Experience. J Clin Aesthet Dermatol. 2012:5:37-50.

63. Krunic A, Ciurea A, Scheman A. Efficacy and tolerance of acne treatment using both spironolactone and a combined contraceptive containing drospirenone. J Am Acad Dermatol. 2008;58:60-2.

64. Layton AM, Eady EA, Whitehouse H, Del Rosso JQ, Fedorowicz Z, van Zuuren EJ. Oral Spironolactone for Acne Vulgaris in Adult Females: A Hybrid Systematic Review. Am J Clin Dermatol. 2017;18:169-91.

65. de Bastos M, Stegeman BH, Rosendaal FR, Van Hylckama Vlieg A, Helmerhorst FM, Stijnen T, et al Combined oral contraceptives: venous thrombosis. Cochrane Database Syst Rev. 2014:CD010813.

66. Fox L, Csongradi C, Aucamp M, du Plessis J, Gerber M. Treatment Modalities for Acne. Molecules. 2016;21.pii:E1063.

67. Cooper AJ, Harris VR. Modern management of acne. Med J Aust. 2017;206:41-5.

68. Dispenza MC, Wolpert EB, Gilliland KL, Dai JP, Cong Z, Nelson AM, et al. Systemic isotretinoin therapy normalizes exaggerated TLR-2-mediated innate immune responses in acne patients. J Invest Dermatol. 2012;132:2198-205.

69. Melnik BC. Isotretinoin and Fox01: A scientific hypothesis. Dermatoendocrinol. 2011;3:141-65

70. Bagatin E. Oral isotretinoin: the most promising dermatological off-label uses. Exp Rev Dermatol. 2010;5:617-26.

71. Nickle SB, Peterson N, Peterson M. Updated physician's guide to the off-label uses of oral isotretinoin. J Clin Aesthet Dermatol. 2014;7:22-34.

72. Sbidian E, Vicaut É, Chidiack H, Anselin E, Cribier B, Dréno B, et al. A randomizedcontrolled trial of oral low-dose isotretinoin for difficult-to-treat papulopustular rosacea. J Invest Dermatol. 2016;136:1124-9.

73. Bagatin E, Guadanhim LR, Enokihara MM, Sanudo A, Talarico S, Miot HA, et al. Low-dose oral isotretinoin versus topical retinoic acid for photoaging: a randomized, comparative study. Int J Dermatol. 2014;53:114-22.

74. de Souza Leão Kamamoto C, Sanudo A, Hassun KM, Bagatin E. Low-dose oral isotretinoin for moderate to severe seborrhea/seborrheic dermatitis: a randomized and comparative trial. Int J Dermatol. 2017;56:80-5.

75. Rademaker M. Adverse effects of isotretinoin: A retrospective review of 1743 patients started on isotretinoin. Australas J Dermatol. 2010;51:248-53.

76. Brzezinski P, Borowska K, Chiriac A, Smigielski J. Adverse effects of isotretinoin: A large, retrospective review. Dermatol Ther. 2017;14: e12483.

77. Rademaker M. Isotretinoin: dose, duration and relapse. What does 30 years of usage tell us? Australas J Dermatol. 2013;54:157-62.

78. Hansen TJ, Lucking S, Miller JJ, Kirby JS, Thiboutot DM, Zaenglein AL. Standardized laboratory monitoring with use of isotretinoin in acne. J Am Acad Dermatol. 2016;75:323-8.

79. Sladden MJ, Harman KE. What is the chance of a normal pregnancy in a woman whose fetus has been exposed to isotretinoin. Arch Dermatol. 2007;143:1187-8.

80. Halvorsen JA, Stern RS, Dalgard F, Thoresen M, Bjertness E, Lien L. Suicida ideation, mental health problems and social impairment are increased in adolescents with acne: a population-based study. J Invest Dermatol. 2011:131:363-70.

81. Marron SE, Tomas-Araones L, Boira S. Anxiety, depression, quality of life and patient satisfaction in acne patients treated with oral isotretinoin. Acta Derm Venereol. 2013;93:701-6.

82. Huang $\mathrm{YC}$, Cheng YC. Isotretinoin treatment for acne and risk of depression: $A$ systematic review and meta-analysis. J Am Acad Dermatol. 2017;76:1068-1076. e9.

83. Etminan M, Bird ST, Delaney JA, Bressler B, Brophy JM. Isotretinoin and risk for inflammatory bowel disease: a nested case-control study and meta-analysis of published and unpublished data. JAMA Dermatol. 2013;149:216-20.
84. Alhusayen RO, Juurlink DN, Mamdani MM, Morrow RL, Shear NH, Dormuth CR; Canadian Drug Safety and Effectiveness Research Network. Isotretinoin use and the risk of inflammatory bowel disease: a population-based cohort study. J Invest Dermatol. 2013;133:907-12.

85. Margolis DJ, Fanelli M, Hoffstad 0, Lewis JD. Potential association between the oral tetracycline class of antimicrobials used to treat acne and inflammatory bowel disease. Am J Gastroenterol. 2010;105:2610-6.

86. Lee YH, Scharnitz TP, Muscat J, Chen A, Gupta-Elera G, Kirby JS. Laboratory monitoring during isotretinoin therapy for acne: a systematic review and metaanalysis. JAMA Dermatol. 2016;152:35-44.

87. Sampaio SAP, Bagatin E.A 65-year experience treating acne, including 26 years with oral isotretinoin. An Bras Dermatol. 2008; 834:361-7.

88. Shinkai K, McMichael A, Linos E. Isotretinoin laboratory test monitoring-a call to decrease testing in an era of high-value, cost-conscious care. JAMA Dermatol. 2016;152:17-9

89. Boyraz N, Mustak PK. Comparison of the efficacies of intermittent and continuous low-dose isotretinoin regimens in the treatment of moderate acne vulgaris. Int $J$ Dermatol. 2013;52:1265-7.

90. Rademaker M, Wishart JM, Birchall NM. Isotretinoin $5 \mathrm{mg}$ daily for low-grade adult acne vulgaris - a placebo-controlled, randomized double-blind study. J Eur Acad Dermatol Venereol. 2014;28:747-54.

91. Dhaked DR, Meena RS, Maheshwari A, Agarwal US, Purohit S. A randomized comparative trial of two low-dose oral isotretinoin regimens in moderate to severe acne vulgaris. Indian Dermatol Online J. 2016 ;7:378-85

92. Schmitt JV, Tavares M, Cerci FB. Adult women with acne have a higher risk of elevated triglyceride levels with the use of oral isotretinoin. An Bras Dermatol. 2011;86:807-10.

93. Cetinözman F, Aksoy DY, Elçin G, Yıldız BO. Insulin sensitivity, androgens and isotretinoin therapy in women with severe acne. J Dermatolog Treat. 2014;25:11922.

94. Thielitz A, Sidou F, Gollnick H. Control of microcomedone formation through a maintenance treatment with adapalene gel $0.1 \%$. J Eur Acad Dermatol Venereol. 2007;21:747-53.

95. Morales-Cardona CA, Sánchez-Vanegas G. Tasa de recaída y factores pronóstico de recaída después del tratamiento con isotretinoína oral en pacientes con acné quístico. Acne Relapse Rate and Predictors of Relapse Following Treatment with Oral Isotretinoin. Actas Dermosifiliogr. 2013; 104:61-6.

96. Chularojanamontri L, Tuchinda P, Kulthanan K, Pongparit K. Moisturizers for acnewhat are their constituents. J Clin Aesthet Dermatol. 2014;7:36-44.

97. Araviiskaia E, Dréno B. The role of topical dermocosmetics in acne vulgaris. J Eur Acad Dermatol Venereol. 2016;30:926-35

98. Larsen RL. Over-the-counter treatments for acne and rosacea. Semin Cutan Med Surg. 2016;35:87-95.

99. Barros BS, Zaenglein AL. The Use of Cosmeceuticals in Acne: Help or Hoax? Am J Clin Dermatol. 2017;18:159-63.

100. Wohlrab J, Kreft D. Niacinamide-mechanisms of action and its topical use in dermatology. Skin Pharmacol Physiol. 2014;27:311-5

101. Kim SJ, Baek JH, Koh JS, Bae MI, Lee SJ, Shin MK. The effect of physically applied alpha hydroxy acids on the skin pore and comedone. Int J Cosmet Sci. 2015;37:519-25

102. Draelos Z, Lewis J, McHugh L, Pellegrino A, Popescu L. Novel retinoid ester in combination with salicylic acid for the treatment of acne. J Cosmet Dermatol. 2016;15:36-42.

103. Dreno B, Castell A, Tsankov N, Lipozencic J, Serdaroglu S, Gutierrez V, et al. Interest of the association retinaldehyde/glycolic acid in adult acne. J Eur Acad Dermatol Venereol. 2009:23:529-32.

104. Monfrecola G, Cacciapuoti S, Capasso C, Delfino M, Fabbrocini G. Tolerability and camouflaging effect of corrective makeup for acne: results of a clinical study of a novel face compact cream. Clin Cosmet Investig Dermatol. 2016;9:307-13.

105. Mahajan BB, Garg G. Therapeutic efficacy of intralesional triamcinolone acetonide versus intralesional triamcinolone acetonide plus lincomycin in the treatment of nodulocystic acne. Indian J Dermatol Venereol Leprol. 2003;69:217-9.

106. Levy LL, Zeichner JA. Management of acne scarring, part II: a comparative review of non-laser-based, minimally invasive approaches. Am J Clin Dermatol. 2012:13:331-40.

107. El-Domyati M, Hosam W, Abdel-Azim E, Abdel-Wahab H, Mohamed E Microdermabrasion: a clinical, histometric, and histopathologic study. J Cosmet Dermatol. 2016;15:503-13

108. Marczyk B, Mucha P, Budzisz E, Rotsztejn H. Comparative study of the effect of $50 \%$ pyruvic and $30 \%$ salicylic peels on the skin lipid film in patients with acne vulgaris. J Cosmet Dermatol. 2014;13:15-21.

109. Puri N. Efficacy of modified Jessner's peel and $20 \%$ TCA versus $20 \%$ TCA peel alone for the treatment of acne scars. J Cutan Aesthet Surg. 2015;8:42-5. 
110. Abdel Meguid AM, Elaziz Ahmed Attallah DA, Omar H. Trichloroacetic acid versus salicylic acid in the treatment of acne vulgaris in dark-skinned patients. Dermatol Surg. 2015;41:1398-404.

111. Dayal S, Amrani A, Sahu P, Jain VK. Jessner's solution vs. $30 \%$ salicylic acid peels: a comparative study of the efficacy and safety in mild-to-moderate acne vulgaris. J Cosmet Dermatol. 2017;16:43-51.

112. Alba MN, Gerenutti M, Yoshida VM, Grotto D. Clinical comparison of salicylic acid peel and LED-Laser phototherapy for the treatment of acne vulgaris in teenagers. J Cosmet Laser Ther. 2017;19:49-53.

113. Sakamoto FH, Lopes JD, Anderson RR. Photodynamic therapy for acne vulgaris: a critical review from basis to clinical practice. Part I. Acne vulgaris: when and why consider photodynamic therapy. J Am Acad Dermatol. 2010;63:183-93.

114. Barbaric J, Abbott R, Posadzki P, Car M, Gunn LH, Layton AM, et al. Light therapies for acne: abridged Cochrane systematic review including GRADE assessments. Br J Dermatol. 2018;178:61-75.

115. Politi Y, Levi A, Enk CD, Lapidoth M. Integrated cooling-vacuum-assisted 1540-nm erbium:glass laser is effective in treating mild-to-moderate acne vulgaris. Lasers Med Sci. 2015;30:2389-93.

116. Clinicaltrials.gov [Internet]. Paithankar D. Pivotal Study of Sebacia Microparticles in the Treatment of Acne Vulgaris, Annual meeting of the American Society for Laser Medicine and Surgery, 2014 [cited 2018 Feb 18]. Available from: https:// clinicaltrials.gov/ct2/show/NCT02217228.

117. Lanoue J, Goldenberg G. Acne scarring: a review of cosmetic therapies. Cutis. 2015;95:276-81.

118. Gadkari R, Nayak C. A split-face comparative study to evaluate efficacy of combined subcision and dermaroller against combined subcision and cryoroller in treatment of acne scars. J Cosmet Dermatol. 2014:13:38-43.

119. You HJ, Kim DW, Yoon ES, Park SH. Comparison of four different lasers for acne scars: Resurfacing and fractional lasers. J Plast Reconstr Aesthet Surg. 2016;69:e87-95
120. Brauer JA, Kazlouskaya V, Alabdulrazzaq H, Bae YS, Bernstein LJ, Anolik R, et al. Use of a picosecond pulse duration laser with specialized optic for treatment of facial acne scarring. JAMA Dermatol. 2015;151:278-84.

121. Chandrashekar BS, Sriram R, Mysore R, Bhaskar S, Shetty A. Evaluation of microneedling fractional radiofrequency device for treatment of acne scars. J Cutan Aesthet Surg. 2014;7:93-7.

122. Taylor MB, Zaleski-Larsen L, McGraw TA. Single session treatment of rolling acne scars using tumescent anesthesia, 20\% trichloracetic acid extensive subcision and fractional C02 laser. Dermatol Surg. 2017:43(Suppl 1):S70-S74

123. Abdel Hay R, Shalaby K, Zaher H, Hafez V, Chi CC, Dimitri S, et al. Interventions for acne scars. Cochrane Database Syst Rev. 2016;4:CD011946.

124. Berlim MT, Fleck MP. "Quality of life": a brand new concept for research and practice in psychiatry. Rev Bras Psiquiatr. 2003;25:249-52.

125. Kellett SC, Gawkrodger DJ. The psychological and emotional impact of acne and the effect of treatment with isotretinoin. Br J Dermatol. 1999;140:273-82.

126. Rapp DA, Brenes GA, Feldman SR, Fleischer AB Jr, Graham GF, Dailey M, et al. Anger and acne: implications for quality of life, patient satisfaction and clinical care. Br J Dermatol. 2004:151:183-9.

127. Dalgard F, Gieler U, Holm Jø, Bjertness E, Hauser S. Self-esteem and body satisfaction among late adolescents with acne: results from a population survey. Am Acad Dermatol. 2008;59:746-51.

128. Kamamoto CSL, Hassun KM, Bagatin E, Tomimori J. Acne-specific quality of life questionnaire (Acne-QoL): translation, cultural adaptation and validation into Brazilian-Portuguese language. An Bras Dermatol. 2014;89:83-90.

129. Patrick DL, Deyo RA. Generic and disease-specific measures in assessing health status and quality of life. Med Care. 1989;27(Supp I):S217-32

130. Klassen AF, Newton JN, Mallon E. Measuring quality of life in people referred for specialist care of acne: comparing generic and disease-specific measures. J Am Acad Dermatol. 2000;43:229-33.

131. Dumont-Wallon G, Dréno B. Specificity of acne in women older than 25 years. Presse Med. 2008:37:585-91.

Approval of the final version of the manuscript; Conception and planning of the study; Elaboration and writing of the manuscript; Obtaining, analyzing and interpreting the data; Effective participation in research orientation; Intellectual participation in propaedeutic and/or therapeutic conduct of the cases studied; Critical review of the literature; Critical review of the manuscript

Thais Helena Proença de Freitas ORCID 0000-0002-5594-3837

Approval of the final version of the manuscript; Conception and planning of the study; Elaboration and writing of the manuscript; Obtaining, analyzing and interpreting the data; Effective participation in research orientation; Intellectual participation in propaedeutic and/or therapeutic conduct of the cases studied; Critical review of the literature; Critical review of the manuscript

Maria Cecilia Rivitti-Machado $\quad$ (ID) ORCID 0000-0003-2910-7330

Approval of the final version of the manuscript; Conception and planning of the study; Elaboration and writing of the manuscript; Obtaining, analyzing and interpreting the data; Effective participation in research orientation; Intellectual participation in propaedeutic and/or therapeutic conduct of the cases studied; Critical review of the literature; Critical review of the manuscript

Beatriz Medeiros Ribeiro

ORCID 0000-0002-2171-9378

Approval of the final version of the manuscript; Conception and planning of the study, Elaboration and writing of the manuscript; Obtaining, analyzing and interpreting the data; Effective participation in research orientation; Intellectual participation in propaedeutic and/or therapeutic conduct of the cases studied; Critical review of the literature; Critical review of the manuscript

Samanta Nune ORCID 0000-0001-5846-3372

Critical review of the literature; Critical review of the manuscript

Marco Alexandre Dias da Rocha D ORCID 0000-0003-1090-177X

Approval of the final version of the manuscript; Conception and planning of the study; Elaboration and writing of the manuscript; Obtaining, analyzing and interpreting the data; Effective participation in research orientation; Intellectual participation in propaedeutic and/or therapeutic conduct of the cases studied; Critical review of the literature; Critical review of the manuscript

How to cite this article: Bagatin E, Freitas THP, Rivitti-Machado MC, Ribeiro BM, Nunes S, Rocha MA. Adult female acne: a guide to clinical practice. An Bras Dermatol. 2019;94(1):62-75. 